
VI.-Remains of a Roman Silver Refinery at Silchester. By W. GowLand, Esq.,
F.S.A., F.C.S., Associate of the Royal School of Mines.

Read 3rd May, 1900.

The importance of Silchester as a seat of industrial activity has been enhanced by the discovery in 1894 of some metallurgical remains, of a unique character, which indicate that near the spot where they were found there had once been a silver refinery. Unfortunately they were not found in situ. They had been cast away as rubbish.

The débris, which are of a very fragmentary nature, were handed to me by Messrs. Fox and Hope for examination in the following year. They presented such an unpromising appearance that I laid them aside until a few weeks ago, when I commenced their investigation. I had not proceeded far with their analysis before it was evident that they were of extreme interest and importance; that they

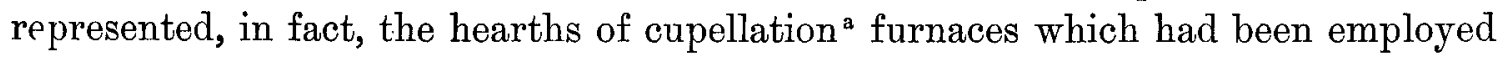
for the extraction of silver from copper, and for the removal of copper from impure silver.

The discovery of these fragments of hearths is of considerable metallurgical and archæological interest, as, so far as I am aware, no similar hearths of the

a When lead containing silver is melted with free access of air a fusible oxide of lead (litharge) is formed on its surface. This may either be allowed to flow away, or it may be absorbed by the vessel or hearth in which the lead is melted if these are made of a porous material. In either case the whole of the lead is oxidised and removed, and pure silver remains. If impure silver is mixed with lead and treated in this way the impurities present are oxidised along with the lead, dissolve in the litharge, and are removed with it. This process is termed cupellation.

VOL. LVII. 
Roman period have yet been found in any of the countries which once formed part of the empire. Not even in Laurion nor in Spain, where the production of silver was undoubtedly great both in Roman and much earlier times, have any been unearthed.

From it we also learn for the first time that the Romans in refining impure silver, and in extracting silver from copper, practised a method of cupellation entirely different from that which they employed at mines for extracting silver from argentiferous lead.

At the Roman mines in Britain, where silver was obtained by the cupellation of the lead from the smelting furnaces, the metal, owing to the general purity of the ores, would usually be sufficiently pure for minting or industrial purposes. Sometimes, however, as for example when ores containing much copper and other impurities were treated, the silver obtained from them would be impure, low in fineness, and unsuitable for practical uses.

In the latter case it was then necessary to submit the crude metal to a refining process. This was evidently conducted in a special furnace, by cupelling it with lead in sufficient quantities to remove the impurities, the chief of which was generally copper. The process was rarely performed at mines, but usually at mints and refineries.

The débris found at Silchester are, as will be demonstrated, the remains of the hearths of furnaces specially adapted for this refining process.

The remains consist of rough lumps of refractory material saturated with oxides of lead and copper, which in parts have been converted into carbonates through exposure to the weather. The freshly fractured surfaces of all are of a brownish red colour with small patches of green (carbonate of copper) and white (carbonate of lead) interspersed. With the exception of a thin upper layer, which is vesicular, they are very compact in structure. They are not slag but furnace débris. All the pieces are very closely alike in appearance, but, when submitted to chemical analysis, it was found that they could be divided into two groups, $A$ and $B$, each group representing the hearth of a distinct furnace. A considerable quantity of metal, in the form of globules, was disseminated through the mass of the pieces A. The pieces $B$, on the other hand, were only encrusted with metal on the upper surface and contained none in their mass.

In addition to the above, there were also found some fragments of litharge, containing only a small quantity of oxide of copper and one globule of silver, which had been produced in another furnace, in the final purification of the crude silver - obtained on the hearth в. No remains of the hearth of this furnace were found. 
I made a careful analysis of the pieces $\mathrm{A}$ and $\mathrm{B}$, the metallic portions being: first separated, with the following results:

\section{Composition of the Hearths.}

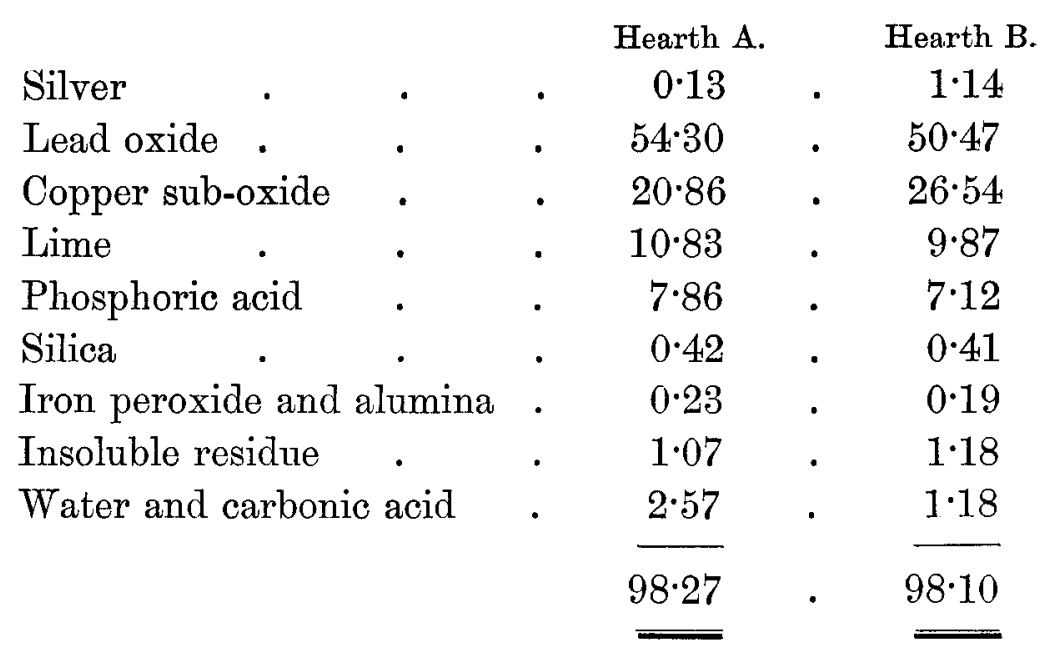

The composition of the pieces, as shown by the analyses, proves clearly that they are portions of the "working bottoms," or hearths of furnaces, in which argentiferous copper was cupelled with lead for the extraction of its silver, and in which silver containing much copper was purified. The comparative absence of lime, excepting that existing in the state of phosphate of lime, and the presence of alumina and silica only in minute proportions, prove, in addition, that the material of which the hearths had been constructed was bone-ash, without any admixture of other substances, the same material, in fact, which is employed at the present day in furnaces for refining silver. I may say, in passing, that the earliest reference to this use of bone-ash, which I have so far been able to find, is in: the Summa Perfectionis of the alchemist Geber, who is said to have lived about 700 A.D. ${ }^{b}$

That this material was so used by the Romans had not hitherto been demon-

a Bone-ash consists chiefly of phosphate of lime.

b Geber, Summa perfectionis magisterii (Venice, 1875), cap. 81. "Sunt autem duo in hujus. perdurantia examine perfectionis corpora, sol, scilicet, et luna, propter bonam compositionem que per bonam mixtione $m$ resultat, et illorum puram substantiam. Narremus igitur modum illius ut tollatur cinis cribellatus aut calx aut pulvis ossium animalium combustorum aut horum omnium commixtio. aut quorundam."

Q 2 
strated, and we owe to the excavations at Silchester the discovery of this interesting fact. ${ }^{\text {a }}$

That the Romans were acquainted with the special properties bone-ash possesses of resisting the corrosive action of molten litharge, and of absorbing it as readily as blotting-paper absorbs water, properties which make it the best possible substance for the process of refining silver by means of lead, is an important testimony to their close observation of the physical characters of materials and their power of utilising them for practical purposes.

For the elucidation of the imperfect remains which have come down to us of ancient industries in Europe, it is always profitable to consider similar industries in countries which, from their geographical positions or other causes, have not participated in the progress of western culture, and where the old simple processes are still in existence.

In a previous communication ${ }^{b}$ to the Society, I have pointed out that the conditions under which metallurgical operations were practised in Japan, in comparatively early times, were closely analogons to those which prevailed in Europe during the period of Roman supremacy; and that the simple methods and appliances then in use still survive in some districts of that country. I propose, therefore, and, I think, I may venture do so without being charged with rashness, to reconstruct the old Roman silver refining furnace from the data afforded by the Japanese furnace used for the same operation. And, especially so, as the reconstruction is rendered comparatively easy owing to the remains found at

a All the fragments of Roman cupellation hearths which had previously been found consisted only of clayey marl; but in the following analysis of a slag from Thoricos, near Laurion, given in Le Laurium by A. Cordella, p. 101, it will be seen that $2 \cdot 4$ per cent. of phosphoric acid is present. It is quite possible that the phosphoric acid in this slag may have been derived from the smelting of cupellation hearths along with the ore from the mines, and if so bone-ash had been employed there. Whether this slag was of Greek or Roman origin is uncertain, as although the mines of laurion had long been worked by the Greeks, they came into the possession of the Romans in 146 в.C.

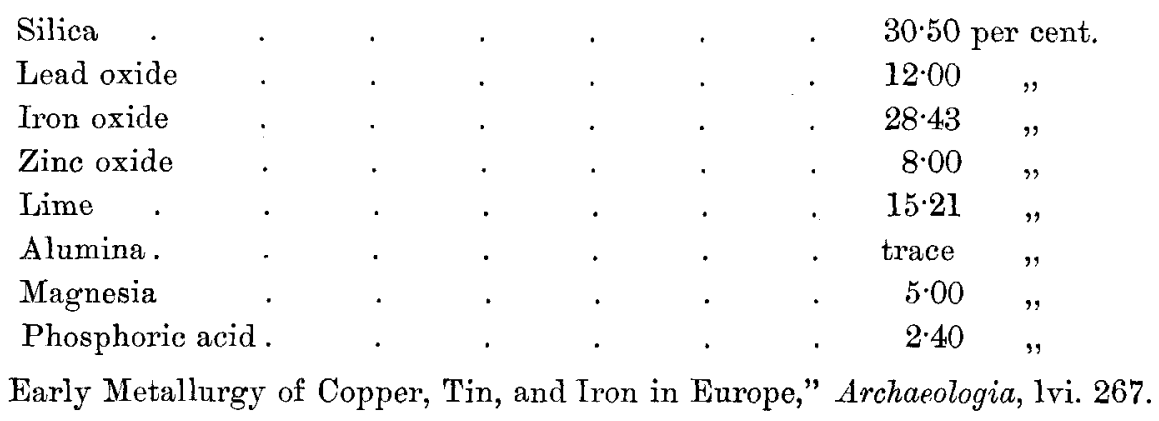


Silchester being those of the essential part of the furnace, viz. the working hearth on which the operations were conducted. Also, because they show by their composition and character the manner in which the furnace was worked. The reconstruction is besides still further simplified by the close resemblance of the remains to the fragments obtained on breaking up similar Japanese hearths of known dimensions; an important feature, which enables us to deduce from them the shape and approximate size of the hearths of the furnaces of which they are the débris.

As the reconstruction of the Roman furnace will be made clearer and more intelligible if we first consider the structure of a Japanese furnace, I will briefly describe a typical one which was still in use in 1880, and which I had frequent opportunities of studying (fig. 1).

The furnace was of the simplest construction. A rectangular hole 2 feet 6 inches long, 2 feet 6 inches broad, and about 1 foot or 1 foot
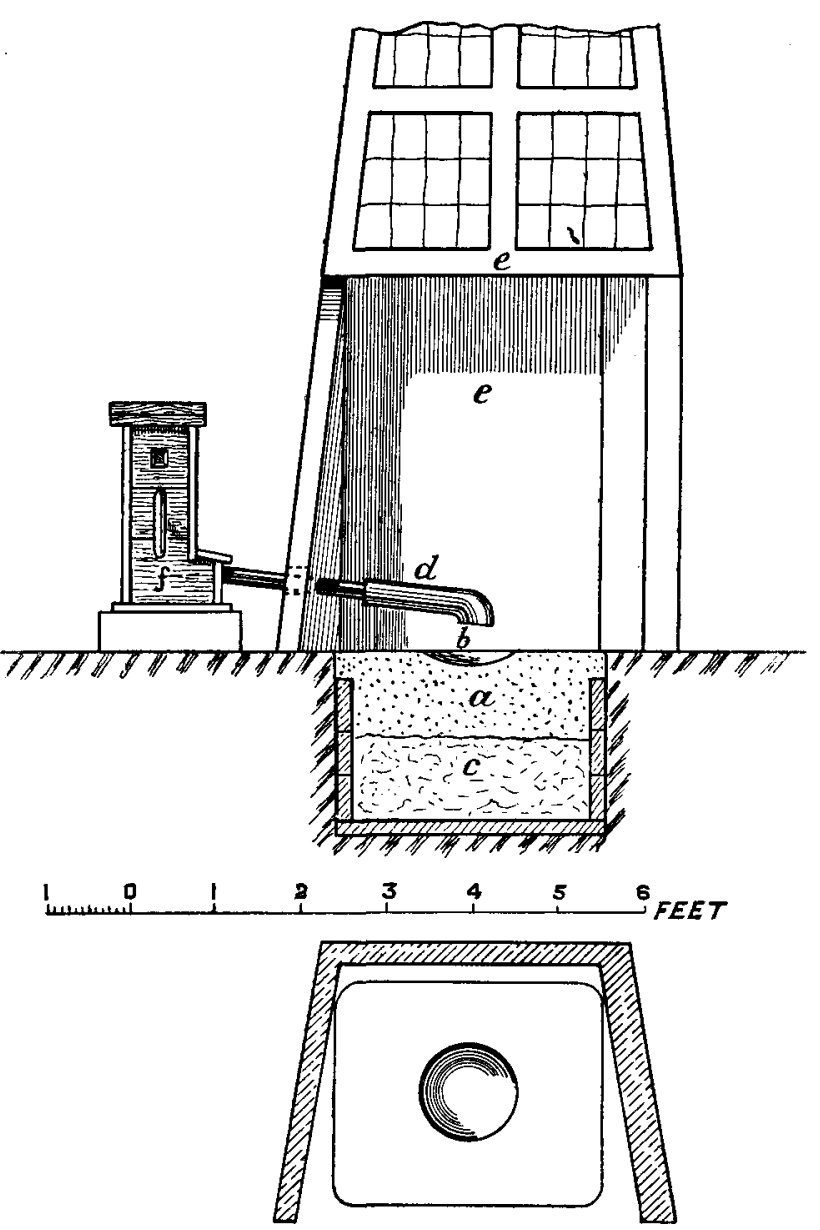

Fig. 1. Japanese cupellation furnace. Plan and Sectional Elevation.

6 inches deep, was dug in the floor of the cupellation room. In this a wooden box, open at the top, and of approximately the same dimensions as the hole, was fixed as a lining. In some refineries the lining consisted only of rough slabs of stone. The lower half of the box was filled with dry clay $(c)$, as shown in fig. 1, and the upper half with charcoal ash $(a)$ which had been previously well washed with water to remove the soluble alkaline matter. These were beaten down until quite solid and level. A shallow circular dish-like cavity (b) about 12 inches to 14 inches in diameter and $1 \frac{1}{2}$ inch to $2 \frac{1}{2}$ inches in depth was scraped out near the middle of the upper surface of the charcoal ash and carefully smoothed. This formed the working hearth. A row of clay slabs set up vertically, about 7 inches high, or a clay wall 
as shown in fig. 4, was then built up around the cavity, at a distance of about 5 or 6 inches from its periphery, an opening 8 inches wide being left in front. The top was closed by several clay slabs which rested on the upper edges of the row surrounding the hearth. A clay tube or twyer (fig. $1(d)$ ) was fixed between two of the side slabs to admit a blast of air from a bellows. The furnace was then ready for use. Each furnace was always surmounted by a wide hoodlike chimney of wattle work coated with clay to carry off the fumes (fig. $1(e e)$ and fig. 4).

The Roman furnace was, I hold, essentially of the same construction, excepting that bone-ash and not wood-ashes was used as the material of the

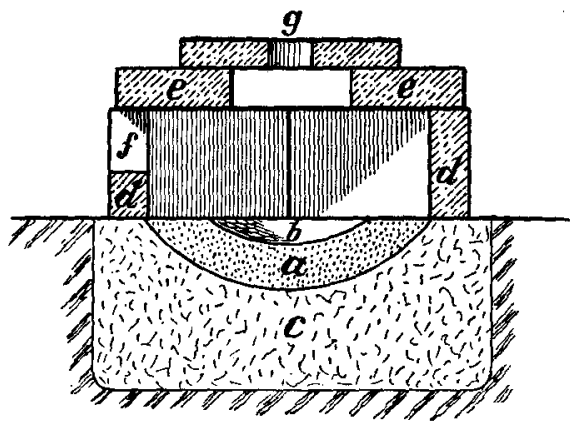

Section on the line $A$ B.

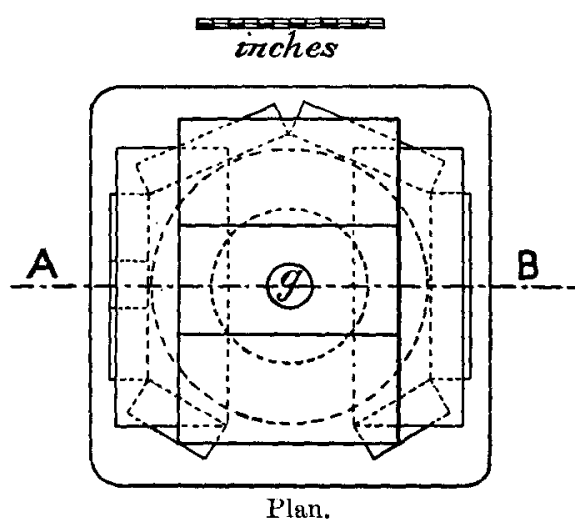

Fig. 2. Roman cupellation furnace. working part of the hearth, and the width of the hearth cavity did not exceed 12 inches. That the hearth must have been similarly enclosed by a row of clay slabs is indicated by the extremely high temperature to which the fragments have been exposed, as this could not have been attained in an open furnace.

In figs. 2 and 3 is given a diagrammatic representation of the Roman cupellation furnace for the purification of crude silver, as. reconstructed from the remains found at Silchester and the data I have specified above.

In figs. 2 and $3, a$ is the working hearth of bone-ash, resting on a stratum of dry clay or marl (c), the whole filling a rectangular hole excavated in the ground of the furnace room. That the lower portion of the hearth was made of the latter materials is, I think, almost certain, as otherwise some bone-ash unsaturated with oxides would have been found. There is, however, a stronger reason for this view, i.e. that bone-ash was not necessary in that part, and, as it doubtless cost more than clay or marl, its use would be confined to the construction of the uppermost stratum where alone it was essential. The upper layers of $a$, or as much as was saturated with oxides, were removed and renewed after each refining operation.

The cavity $b$ in which the metal was cupelled was almost completely encircled 
by bricks or slabs of clay, $d d d d$. Upon these the covering slabs $e e e$, also of clay, were laid. The joints between all these slabs were luted with clay. The hearth was thus perfectly enclosed except at the front, which was kept open to allow the refiner to arrange the fuel and perform other necessary manipulations.

A blast of air from a bellows was admitted to the furnace through a pipe or twyer placed either in the aperture $f$ in one of the side slabs, or in the aperture $g$ in the cover.

No traces of the enclosing walls or of any superstructure were found. This, indeed, could not be expected. They were essentially of a temporary character owing to the necessity of breaking up the upper part of the hearth and removing it after each operation, as it had then become saturated with oxides and could not be further used.

According to Strabo, the furnaces in Spain were prolonged upwards to a considerable height, i.e. they were provided with shaft-like chimnies. ${ }^{a}$ The furnaces at Silchester too were doubtless provided with chimnies on account of the noxious
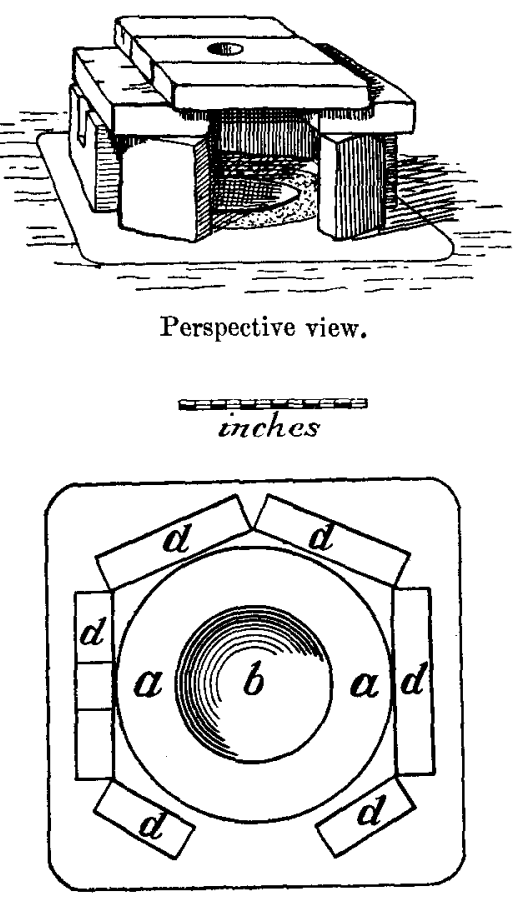

Plan with the covering slabs removed.

Fig. 3. Roman cupellation furnace.

character of the fumes emitted during the process. These chimnies must have been constructed of similar perishable materials to those in Japan, figs. 1 and 4, as no traces of them remain either in Spain or Silchester.

The hearths were, in fact, the only parts which could long resist the ravages of time, and it is not surprising, therefore, that remains of them alone have been found.

We will now proceed to the consideration of the manner in which these furnaces were worked.

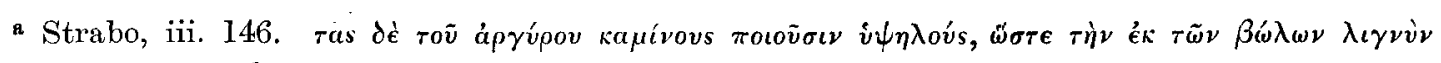

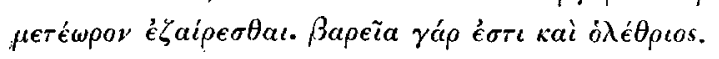

The accuracy of this statement of Strabo has been sometimes questioned owing to the absence, on sites of Roman smelting works, of stones or bricks such as would be used now for the construction of similar chimnies or shafts. The structure of the chimnies of the Japanese furnaces, figs. 1 and 4, shows us, however, that these adjuncts to the hearths can be and are constructed of other and less enduring materials than those now employed in Europe. Strabo's assertion can hence be accepted without doubt. 
In fig. 4 is illustrated the operation of cupellation in progress, as conducted in Japan. The clay slabs surrounding the hearth are shown here slightly incurved, and the top of the furnace is closed by a single slab, but an arrangement of slabs similar to that depicted in figs. 2 and 3, representing the Roman furnace, is not uncommon.

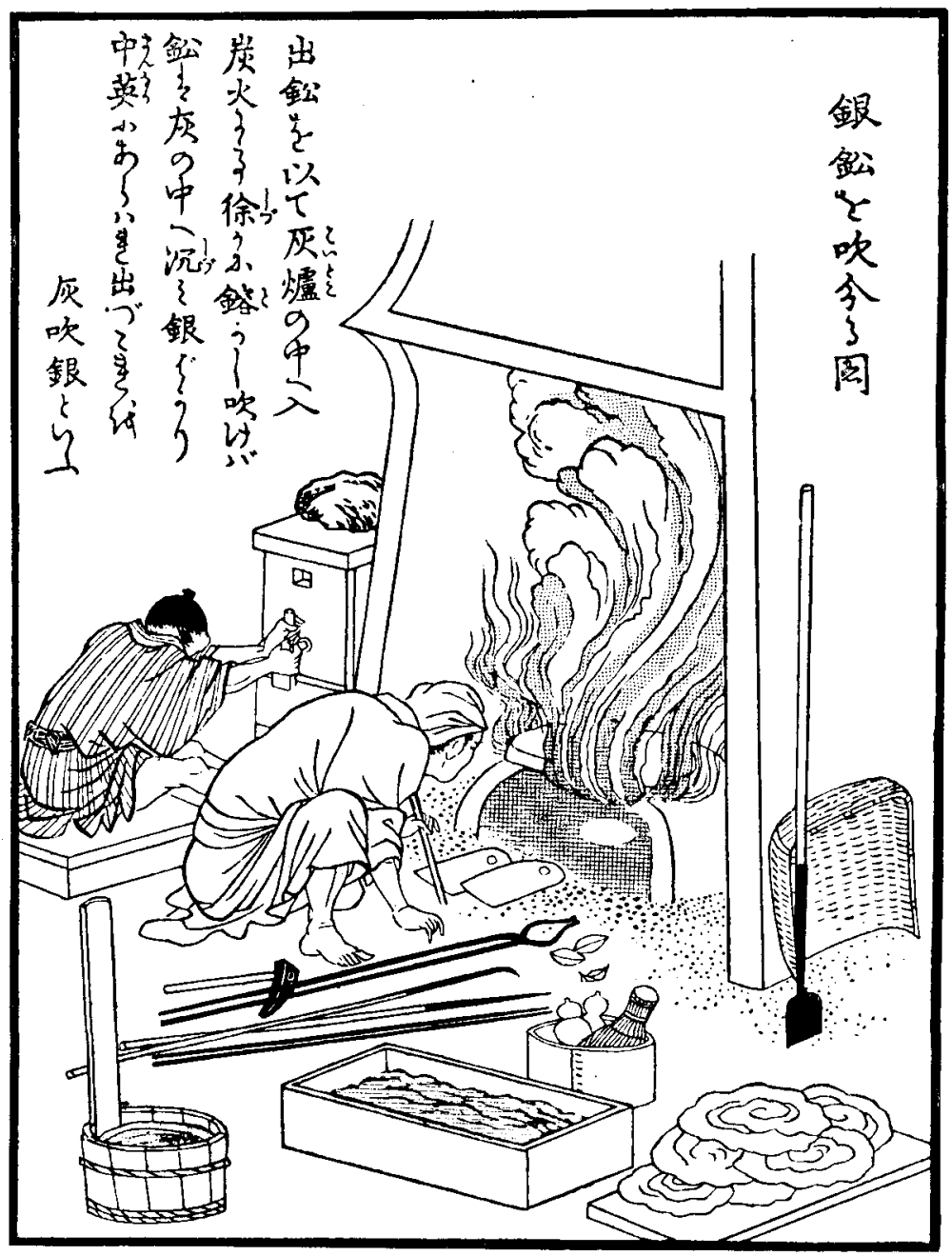

Fig. 4. The cupellation of argentiferous lead in Japan.

The process of refining impure silver by cupelling it with lead was conducted as follows: The shallow cavity in the hearth was filled with charcoal, and when this had become sufficiently ignited, the silver to be refined was placed upon it together with a certain amount of lead. More charcoal was then piled up over the metals and the bellows were started. As soon as the metals had melted and 
the furnace had attained the requisite temperature, the fire was pushed away and piled around the edge of the metallic bath which now filled the cavity in the hearth. By the combined action of the heat and of the air from the bellows the lead was gradually oxidised forming litharge, the copper and other impurities were also converted into oxides at the same time. These oxides dissolved in the melted litharge and were absorbed with it by the hearth.

When the operation was continued sufficiently long and the requisite amount of lead was used the impurities were all removed and a cake of silver remained on the hearth. When, however, the metal treated was chiefly copper, or very impure silver, then pure silver could only be obtained by using a very large amount of lead or by repeating the process. The operations at Silchester were mainly of the latter character.

From the relative proportions of the oxides of lead and copper contained in both the hearths, it is quite clear that the lead used in the cupellation was not all added at the commencement of the operation, but was charged into the furnace from time to time in small and insufficient quantities. The temperature at which the cupellation had to be carried on was, therefore, very much higher than that at which it is conducted in modern furnaces, and, although a saving in lead may thus have been effected, it must have been accompanied by a considerable loss of silver.

Further light on the special uses for which the hearths had been employed is afforded by the analyses I have made of the fragments of metal with which their remains were associated.

The metal A A which was disseminated in granules through the mass of the hearth $A$ was analysed with the following results :

\begin{tabular}{|c|c|c|}
\hline Gold & . & Nil. \\
\hline Silver. & . & $2 \cdot 98$ \\
\hline Copper & . & $78 \cdot 13$ \\
\hline Lead. & . & $16 \cdot 14$ \\
\hline Slag and oxygen & & $2 \cdot 75$ \\
\hline
\end{tabular}

This metal was distributed through the entire mass of the fragments of the hearth A. The reason for this being that the hearth had been so excessively porous that the metal had sunk into it without being oxidised. This had evidently taken place very shortly after cupellation had begun.

VOI. LVII. 
The metal AA may hence be taken as closely representing in composition the metal in the furnace near the commencement of the process.

From these data we can now deduce the functions of the hearth A. They indicate distinctly that this hearth was employed for the extraction of silver from argentiferous copper.

There are two sources from which this copper could have been obtained, viz. (a) from the smelting of argentiferous lead ores mixed with copper ores, and (b) by melting down copper coins containing silver. It is difficult to determine with certainty the precise locality whence the metal was procured in the first case, as in several of the metalliferous districts where extensive lead-mining operations were carried on by the Romans in this country, for example, in Somersetshire, Shropshire, Montgomeryshire, Flintshire, and Anglesey, copper ores occur in close proximity to the lead ores, and must have been occasionally smelted with them. It may, hence, have been produced in any of these districts. All, however, are some distance from Silchester. Yet it must be remembered in considering this question that proximity to the source of production of a raw material is by no means always the chief factor in determining the site of the industry by which it is adapted to useful purposes, also that processes of this nature are very rarely carried on at mines.

In support of the view that the metal may have been derived from the melting down of copper coins containing silver the following evidence may be adduced. The proportions of silver to copper in the metal A A are in round numbers as $4: 96$. Now in the third century, especially from Gallienus to Probus (259 to 282 A.D.), many of the issues of Roman copper coins contained approximately this percentage of silver, and besides these, in the same period and in the next century up to Valentinianus I. (375 A.D.), whilst some contain only from 1 to 2 per cent., others are as high as from 8 to 12 and even 17 per cent. of silver. ${ }^{a}$

It is obvious, therefore, that by a selection, or by an admixture, of these an alloy of similar richness to $\mathrm{A}$ A could be obtained. From such an alloy it would be profitable to extract the silver.

The product of the cupellation of this argentiferous copper on the hearth A was not pure silver, as an insufficiency of lead was used, but an alloy of copper and silver richer in silver than the metal charged into the furnace.

The metal в в, which encrusted the upper surface of the fragments of the hearth $\mathbf{B}$, yielded the following results on analysis :

a Eighty-five analyses of Roman coins, struck between 250 and 375 A.D., consisting chiefly of copper, but containing silver in various proportions from one per cent. upwards, are given in Die 


\begin{tabular}{|c|c|c|c|}
\hline Gold & . & • & $0 \cdot 39$ \\
\hline Silver & . & • & . $32 \cdot 61$ \\
\hline Copper & • & • & $56 \cdot 64$ \\
\hline Lead. & . & • & $8 \cdot 81$ \\
\hline \multirow{2}{*}{\multicolumn{2}{|c|}{ Slag and oxygen }} & • & $1 \cdot 55$ \\
\hline & & & $100 \cdot 0$ \\
\hline
\end{tabular}

It was not, like the metal A A, disseminated through the mass of the hearth, and hence does not represent the original metal treated, but that remaining after partial cupellation. The composition of the hearth B (contains 1.47 per cent. silver) shows, however, that the original metal was richer in silver than the metal of the hearth A before cupellation. I am, therefore, of the opinion that the hearth $\mathrm{B}$ was used for the further cupellation of the copper-silver alloy which was produced

Bronzen und Kupferlegirungen der alten und ältesten Völker, by Dr. Ernst Freiherr von Bibra (Erlangen, 1869), pp. 57-68.

The following table, which I have compiled from von Bibra's comprehensive work, represents fairly the percentages of silver contained in these coins.

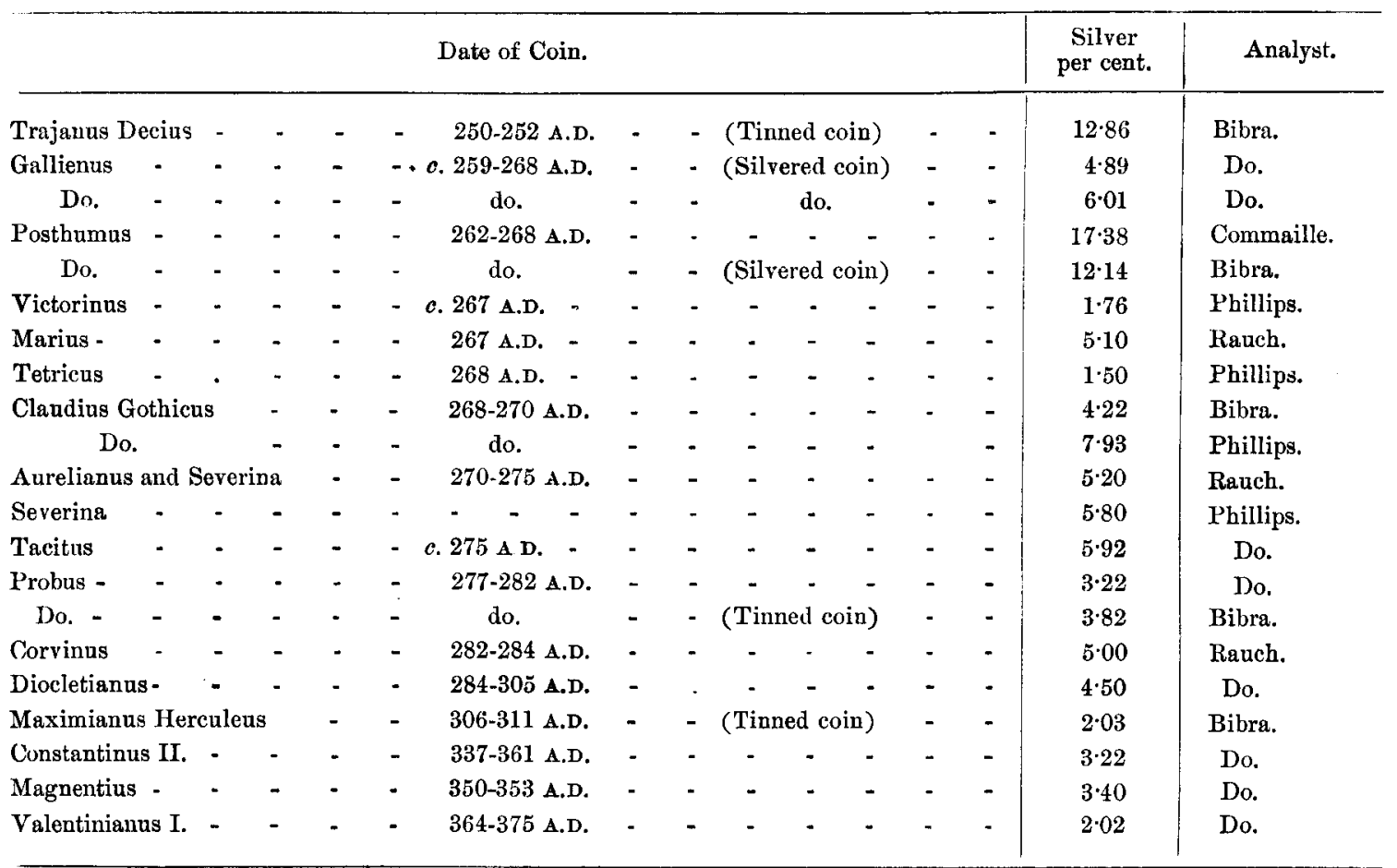


on the hearth $\mathrm{A}$. The resulting metal в $\mathrm{B}$, as shown by the analysis, is still very impure, the ratio of silver to copper being only $37: 63$. This is owing to the too sparing use of lead. It would require to be again cupelled before ordinary refined silver was obtained.

No fragments of the hearth on which the final cupellation was performed were found. The small pieces of litharge, in which a globule of silver was embedded, to which I have already referred, are the sole remains of that operation.

It is further to be noted, and this is a matter of not a little importance, that the physical and chemical character of the fragments of these hearths indicate that the furnaces were not mere appendages of a silversmith's workshop, but that they were employed in operations of considerable magnitude, such, in fact, as would be carried on in a public or government establishment, or for the work of a small mint. As regards the latter, no dies or other appliances relating to minting have been dug up at Silchester, but neither have these been found in most of the cities in which well-known Roman mints were situated. There is, however, additional negative evidence against the assumption that there was a mint in Silchester, in the non-existence of coins which can be shown to have been struck there. We are, hence, almost compelled to infer that the silver produced in the refinery was intended for other purposes than coinage on the spot. What these purposes were the present available data are insufficient to show.

I would again point out that the fragments of these hearths were not found in situ. They had been thrown away as rubbish. This, I think, had happened after the city was abandoned; and certainly not whilst the refinery was in operation as they are so rich in copper and lead. It is, therefore, extremely probable that the refinery was in active existence until near the close of the Roman occupation of Britain.

Finally, it is well known that the process of cupellation practised by both the Greeks and Romans at their mines was carried out in a furnace the hearth of which was constructed of comparatively non-absorbent materials, such as clay and marl, and that the litharge was skimmed off from the surface of the molten metal; but the discovery at Silchester has introduced to us for the first time another process, that of cupellation in a furnace with a hearth consisting of an absorbent material, bone-ash, in which the litharge and impurities were not skimmed off, but were entirely absorbed by the hearth itself. A mode of procedure of which there was hitherto no evidence whatever that it had been practised by the Romans. 